\title{
'Elderly graduates' and a hospital closure programme: the experience of the Camberwell Resettlement Team
}

\author{
Frank Holloway, Consultant Psychiatrist, Camberwell Resettlement Team, \\ St Giles Day Hospital, St Giles Road, London SE5
}

The closure of Britain's large psychiatric hospitals, long foreseen, is now rapidly becoming a reality. Surprisingly little is known about the process and outcome of the relocation of long-stay hospital residents. One area of particular concern is the fate of 'elderly graduate' patients, who are by convention defined as long-stay patients aged over 65 years who came into continuous psychiatric contact before the age of 65 . (More cynically they might be defined as those elderly patients whom our colleagues specialising in the psychiatry of the elderly choose not to take over). This paper documents the experience of a specialist resettlement team working within a declining mental hospital attempting to place 'elderly graduate' hospital residents into community provision.

Since 1987 a specialist multidisciplinary team (the Camberwell Resettlement Team (CRT)) has been working in Cane Hill Hospital, which is due to close in 1992. The CRT's role has been to plan and implement the development of successor services for the functionally mentally ill Cane Hill residents who were the responsibility of Camberwell Health Authority. Camberwell is one of three health districts that have historically used the hospital. The CRT produced and has been working to a strategy document that envisaged the reprovision of the hospital, which is 14 miles from the centre of Camberwell, by a range of residential and day care services (Coming Home to Camberwell, Camberwell Health Authority, 1989). These included a supported housing service (a network of small but well-staffed registered residential homes run by a housing association and staffed by the health authority); a specialist nursing home for more dependent 'elderly graduate' patients; a high support house (an intensively staffed registered mental nursing home for younger, more disturbed patients); a programme of placements in private and voluntary residential and nursing homes; and provision for 'hard to place' patients.

At the time of writing only the placements programme and the supported housing service (SHS) have been implemented; the high support house is to be opened during 1991. Lack of capital funding makes it unlikely that the 'elderly graduate' nursing home will ever be built. The placements service has been previously described (Holloway et al, 1988). The CRT has carried out detailed preparation prior to discharge and has offered continuing follow-up and support to all Camberwell patients who have left the hospital since 1987.

\section{Monitoring the closure process}

In order to monitor the subsequent fate of our 'elderly graduate' patients, all Cane Hill residents over 65 years of age who were the responsibility of the CRT in September 1987 were assessed by nursing members of the team. This 'elderly graduate' sample consisted of patients who had been admitted to longstay wards for the functionally mentally ill and had grown old within the hospital. Patients with a primary diagnosis of dementia, whose current care and reprovision were the responsibility of the psychogeriatric service, were excluded. A pro forma was completed which recorded data on age, sex, and length of stay in hospital. The CAPE Behaviour Rating Scale (BRS) was completed, using ward staff as informants. The Behaviour Rating Scale provided an overall score and a dependency grade (ranging from A, 'no impairment' or 'independent elderly', to E, 'severe impairment' or 'maximum dependency'). The hospital psychiatric diagnosis was recorded. The outcome for the sample, in terms of placement, hospital readmission and death, was hospital.) The remaining 27 patients were not discharged. The early placement failures have been combined with the nondischarged patients for subsequent analysis as the 'in-patient' group.

Patients were discharged to a variety of settings. Eight 'elderly graduates' were discharged to the SHS, a network of four staffed houses providing 21 places which opened in 1989. Elderly residents in the SHS had low CAPE BRS total scores (mean 5.4, range 1-10). At the time of discharge none suffered from marked physical disability, although all remained actively psychiatrically ill. (Interestingly, since the houses opened the increasing disability of the residents is becoming a significant issue within the SHS.) Eight patients were placed in private residential homes for the elderly (mean BRS total score 5.8, 
range 2-18). Six were discharged to nursing homes: these were more dependent (mean BRS total score 14.0 , range $10-28$ ).

The 'discharged' patients were significantly less dependent according to the CAPE scores than the 'non-discharged' patients. Only four of the 22 patients who were successfully discharged were in CAPE grades D and E, compared with 15 of the 29 patients who were not successfully discharged $\left(\chi^{2}=\right.$ $6.0,1$ degree of freedom, $P<0.02$ ). There were no significant differences between the two groups on other parameters.

Eighteen $(35 \%)$ of the 51 patients in the sample had died at follow-up. Death was significantly related to CAPE grade: eight of the 12 patients rated as Grade E were dead at follow-up, compared with ten of the 37 patients of Grades A to $D\left(\chi^{2}=4.6,1\right.$ degree of freedom, $P<0.05$ ). Unsurprisingly, patients who died were older than those who remained alive ( 80.2 years $v .72 .7$ years). Three of the 22 patients who were successfully discharged died during the follow-up period, compared with 15 of the 29 who were not successfully discharged. After three years only 14 of the initial 'elderly graduate' sample remained in the hospital.

\section{Implications}

A number of points emerge from the experience of the CRT. The most dependent patients according to the CAPE BRS were very likely to die during the three year follow-up period. It may therefore be more humane to leave these patients in the declining hospital rather than subject them to the risks of a move to another care setting. This contradicts conventional advice that the most dependent patients should be discharged early in the closure process, and carries with it the risks of exposing these patients to a worsening standard of care and multiple ward moves as the hospital contracts towards closure. There was no evidence that carefully selected patients discharged into appropriate settings after careful preparation were at increased risk of death. However, this may be a false negative result, since the majority of the discharges took place during 1989 and 1990, and clearly only those who were alive at the time were eligible for discharge. The evidence that hospital discharge of elderly former long-stay patients is associated with an increase in death rate is equivocal (Linn et al, 1985). Further large-scale studies on the risks of discharge are required. Despite the vigorous efforts of a placements service that has been highly effective in placing elderly people with dementia, only $27 \%$ of the 'elderly graduates' in the sample were discharged from hospital into private sector residential and nursing homes. Despite the financial incentives to the CHA that were available if patients were discharged (which could have been ploughed back into the local psychiatric service) suitable placements could not be identified for the most disabled elderly patients in the hospital.

Many 'non-discharged' patients died during the follow-up period. The 14 patients remaining in the hospital at follow-up present a variety of clinical problems including active psychiatric symptomatology, physical frailty, incontinence, violence to others and 'institutional' behaviours such as hoarding, stealing, inappropriate sexual behaviour and wandering. They are on average more disabled than the surviving 'discharged' patients. Three elderly schizophrenic women steadfastly refuse to accept that they will have to leave hospital, although efforts to persuade them of the necessity to choose alternative accommodation continue. Finally, the monitoring exercise itself was relatively easy to carry out. Since the team had in any case to identify the needs of its patients and develop a therapeutic relationship with them in order to facilitate placement, making 'objective' ratings of their dependency required no additional resources. The CAPE proved a useful instrument with this population, despite its failure adequately to take account of positive psychiatric symptoms and consequent behavioural disturbance.

The generality of the CRT experience, reflecting the work of a single team within one psychiatric hospital, is clearly open to doubt. There is evidence that the long-stay functionally mentally ill population of Cane Hill is similar to that of other large mental hospitals (Webb \& Clifford, 1988). 'Discharged' patients in this study had a similar mean CAPE Behaviour Rating Scale score to a sample of patients successfully discharged from Springfield Hospital into private residential care (Perkins et al, 1989). The failure to find appropriate placements for the most disabled elderly Cane Hill patients in the private and voluntary sector is therefore likely to afflict other closure programmes. Moreover, it should not be assumed that the problem of 'elderly graduates' is unique to the back wards of mental hospitals. A study of patients who stayed over six months on the acute wards serving the East Lambeth sector of Camberwell identified 11 patients who were over 65 (11 per 100,000 total population). All but one had been in psychiatric contact for many years prior to the survey. The long-term care of this group of patients presented considerable problems for the local services.

Given the difficulties encountered in discharging these 'elderly graduate' patients, and an apparent reluctance to fund specialist purpose-built local services, the outlook for the more disabled patients remaining within this declining psychiatric hospital is very uncertain. It may be that private sector entrepreneurs, identifying an undoubted gap in the market, will move in and develop specialist facilities 
for the more dependent elderly functionally mentally ill. Experience of the fate of elderly psychiatric hospital residents discharged into nursing homes in the United States has been highly problematic (Brown, 1985; Linn et al, 1985). Although it has been argued that comparisons between the private sectors in the USA and Britain are misleading (Perkins et al, 1989), the current British government strategy which specifically encourages a "mixed economy of care" must be a cause for concern.

It is possible that the need for specialised public sector provision for elderly people suffering from a functional mental illness may be recognised, and that the necessary capital and revenue support will be forthcoming. If services for the patients with longterm and severe disabilities are not made available, the hospital closure programme can only progress by the collapsing of hospitals onto residual institutions. Such a strategy may be appropriate for some institutionalised patients. However, this hardly meets aspirations for the development of comprehensive local mental health services, which will come under increasing strain without adequate provision for those who require long-term highly supported residential care.

\section{Acknowledgements}

The assessments were carried out by Sally Mill, Kath Siddle and Colin Wilson. Dr Adrienne Little, Principal Psychologist for the Elderly, suggested the use of the CAPE as an assessment tool.

\section{References}

Brown, P. (1985) The Transfer of Care. Psychiatric Deinstitutionalisation and its Aftermath. London: Routledge.

Holloway, F., Booker, D., Mill, S. et al (1988) Progress and pitfalls in the move out of hospital. The Health Service Journal, 11 August, 910-912.

LiNN, M. W., GUREL, L., Williford, W. O. et al (1985) Nursing home care as an alternative to psychiatric hospitalisation. Archives of General Psychiatry, 42, 544-551.

Perkins, R. E., King, S. \& Hollyman, J. A. (1989) Resettlement of old long-stay psychiatric patients: the use of the private sector. British Journal of Psychiatry. 155, 233-238.

WeBB, Y. \& CLIFFoRd, P. (1988) Warley Hospital: patient needs survey. London: NUPRD.

A full list of references is available on request to the author.

\section{Regional Meeting of the College in Bahrain}

Members and Fellows are reminded that the Regional Meeting of the College in Bahrain was postponed from October 1990 until 28-30 October 1991. The full programme extends from Saturday, 26 October to Sunday, 3 November and includes flights and accommodation in both Cairo and Bahrain. The organisers will be in touch with all participants who registered for the original meeting. Anyone interested in attending who did not register for the original meeting should contact either $\mathrm{Dr} \mathbf{M}$. A. Mawgoud, Severalls Hospital, Boxted Road, Colchester CO4 5HG or Dr Charlotte Kamel, Ministry of Health, PO Box 12, Bahrain. These dates are provisional and are yet to be confirmed by the College. 